\title{
Generation Y and Job Performance: SMEs in Malaysia
}

\author{
Susana William Jalil, Pauline Achan, \\ Dean Nelson Mojolou, Awang Rozaimie
}

Faculty of Business Management, Universiti Teknologi MARA, 94300 Kota Samarahan, Sarawak, Malaysia

susanna@sarawak.uitm.edu.my

\begin{abstract}
The aim of the present study is to examine the impact of personal characteristics namely: physical activity, smoking, drinking, and duration of computer use before taking breaks on performance at work of the "Generation Y" who employed in the Malaysian SMEs. The correlation analyses performed in order to gauge the relationship between individual characteristics and the performance of the 67 respondents who were working at the various SMEs. The key finding indicates that smoking found to have the highest effect. Therefore, this study filled the research gap pertaining to the effective management of manpower in the Malaysian SMEs.
\end{abstract}

Keywords: Individual characteristics; Generation Y; office workers; SMEs; job performance

eISSN 2514-7528 @ 2018. The Authors. Published for AMER ABRA cE-Bs by e-International Publishing House, Ltd., UK. This is an open-access article under the CC BY-NC-ND license (http://creativecommons.org/licenses/bync-nd/4.0/). Peer-review under responsibility of AMER (Association of Malaysian Environment-Behaviour Researchers), ABRA (Association of Behavioural Researchers on Asians) and cE-Bs (Centre for EnvironmentBehaviour Studies), Faculty of Architecture, Planning \& Surveying, Universiti Teknologi MARA, Malaysia.

DOI: https://doi.org/10.21834/jabs.v3i10.307 


\subsection{Introduction}

SMEs have been playing and will continue to play an important role in the national economy to this country. SMEs are significant both in terms of their contribution to total output and total employment in Malaysia (Annie, 2009). The majority of the manufacturing SMEs in Sarawak are located in Kuching division as they are also the largest employers; contributed to about 44 percent of the total SMEs employment, as well as the largest wage payers (Statistic Department, Sarawak Branch, 2010). An increasing number of employees are being employed each year the SMEs have seen diversities in relation to age in the workplace, namely the Baby Boomers, generation $X$ and generation $Y$. Each one of these generations brings with it a different personal characteristic thus job performance.

This study focuses on the individual characteristics of the generation $Y$ employees and its effects on their job performance. According to Feuerstein (2005), Gerr, Marcus and Monteilh (2006), and Village, Rempel and Teschke (2005); individual or personal characteristics comprise age; body mass index; frequency of physical activity enough to perspire; use of vision correction; smoking habits; alcohol drinking habits; and computer information. In their studies, they indicated that individual characteristics may influence the way in which work performed and may change the workers' responses to these. Not only the generations $Y$ are technology savvy, they are self-centred and multitask. The technology allows these generations $Y$ to work flexibly. These young employees were also found to work long hours and saw this as essential for their job and to get ahead (Kelan, Gratton, Mah and Walker, 2009).

Purposive sampling was used to determine the number of population; hence the information will be obtained from specific target groups and this sampling is confined to specific types of people who can provide the desired information for the researchers to run this study. Meanwhile, proportionate stratified random sampling is designed to choose the subjects as a sample in this study. Sixty-seven survey questionnaires were distributed personally to office workers of the SME companies selected earlier. Data was explored using descriptive statistics that include mean and standard deviation.

\subsection{Literature Review}

\subsection{Generation $Y$}

In Malaysia, the Generation $Y$ constitutes about $40 \%$ of the workforce, and they are currently less than 35 years of age. The Generation $Y$ is not only cooperative, but optimistic about the future compare to the Baby Boomer and Generation X co-workers (Gursoy, Maier and Chi, 2008). These authors claimed that Generation Y employees are confident, civic-minded, fast learners, dislike inflexible work schedules and rigid policies and procedures that control them. According to Md. Aminul Islam, Teh Wee Cheong, Dayang Hasliza and Hazry Desa (2011); Kelan et al. (2009) the Generation Y preferred to work long hours and saw this as essential for their job and to get ahead. 


\subsection{Job Performance}

According to Borman and Motowidlo (1993), job performance has two dimensions that are task performance and contextual performance. Based on this study, Borman et al., (1993) have stated that the contextual scale are composed of items measuring leadership, teamwork and positive behavior, consistent with the interpersonal facilitation dimension of contextual performance while the task performance scale included technical knowledge and problem solving items.

Task performance and contextual performance are two distinct of behavior at work that contributes independently for effective outcomes (Borman et al., 1993). Borman et al., (1993) have further mentioned that both task performance and contextual performance describe specific behavior of individual and it can be distinguished from effectiveness that is the impact that behaviors on have outcomes that are valued by the organization. According to Griffin, Neal and Neale (2000) this distinction emphasizes that the performance is defined by behavior itself while effectiveness is the consequences of behavior.

Task performance involves patterns or behaviors that are directly involved in producing goods or services or activities that provide indirect support for the organization's core technical processes (Borman, 2004). The task performance contributes to organizational effectiveness either by transforming the organization raw material as a step toward creating the organization's product or by providing necessary service and maintaining functions such as replenishing the supply of raw material, distributing, coordinating and supervising staff (Griffin et al., 2000; Borman, 2004).

Contextual performance is defined as individual effort that is not directly related to their main task function but is important because they shape the organization social and psychological context that serves as a critical catalyst for task activities and process. When employees help others to complete a task, corporate with their supervisor or suggest improving organization processes, they are engaging in contextual performance (Bormon et al. 1993; Borman 2004). Researchers have been recognized that most important aspect of work behavior and has sometimes been regarded as being synonymous with overall job performance. The contextual contributes to organizational effectiveness by supporting the organizational social and psychological context with which technical core must function (Borman et al., 1993).

\subsection{Individual Characteristics}

According to Feuerstein (2005), Gerr, Marcus and Monteilh (2006); Village, Rempel and Teschke (2005), ljmker, Huymans, Blatter, van der Beek, van Mechelan, and Bongers (2007); individual characteristics include age, gender, physical activity, alcohol drinking habits, smoking habits and Computer Use Information.

Physical Activity. Employees who exercised before work were found to be able to handle the workload demands better by $74 \% ; 79 \%$ reported that their mental and interpersonal performance was better; as a result, $27 \%$ of the employees were able to concentrate on their work (Miranda, Viikari-Juntra, Martikainen, Takala, \& Riihimaki, 2001; Ortho-McNeil, 2008; 
Feurstein, Shaw, Nicholas and Huang, 2004; Janwantanakul, Pensri, Jiamjarasrangsri and Sinsongsook, 2008). Office workers today are experiencing increasing work demands, and it has become problematic for employees and organizations alike (Sonnentag \& Zijlstra, 2006 ) in relation to employees' job performance. Apart from augmenting the importance of intelligence (the demand for skilled and intelligence workforce) and job productivity, promoting healthy lifestyles (exercises) and stress management among Generation $Y$ is equally important in today's workplace. Many organizations have provided their employees with fitness facilities as a fringe benefit for their employees because studies have shown that it can help them cope with the consequences of stress related to work demand.

Smoking Habits. Based on Lundborg (2007), smoke breaks among employees are considered disruptive as it takes time away from work and may view as unfair by fellow workers. Nonetheless, this finding is consistent with the finding from a study by Conway, Woodruff and Hervig (2007) that three 15-minute smoking breaks a day amounted to a full year of a worker's life spent smoking. Thus, it is concluded that smoking habits have a positive effect on employees' job performance. The association between smoking and sick leave is eminent. There may be many smoking-related health problems that have consequences on health and economy. Tobacco not only damages the health of smokers but may also harm the economic health of workers. Therefore, the tendency to be absent from work is high thus affecting their job performance. Studies have also found that smoke breaks among employees are considered disruptive as it takes time away from work and may be viewed as unfair by fellow workers (Lundborg, 2007). One survey found that three 15minute smoking breaks a day amounted to a full year of a worker's life spent smoking. (Conway, Woodruff and Hervig, 2007).

Alcohol Drinking. Researchers have examined the alcohol drinking habits and work connection by looking at either job characteristics as influencing drinking or drinking patterns as they affect work performance (Maniam, 1994; Velicer, Friedman, Fava, Gulliver, Keller, Sun, Ramelson, and Prochaska, 2006; Marchand and Blanc, 2011). Although Generation Y were found related to drinking occasions in bars, pubs and restaurants (Teagle, Mueller and Lockshin, 2010), there are limited substantive evidences on its contribution among Gen $Y$ employees in Malaysia. Nonetheless, alcohol misuse afflicts a significant part of the working population irrespective of age. In Malaysia, $46 \%$ of adults working full-time reported heavy drinking and $22 \%$ reported drinking alcohol at work. It was also reported that the higher the class, the higher the prevalence of alcohol use (Maniam, 1994). Alcohol misuse is of great concern for employers and society since it has been associated with absenteeism because according to Marchand and Blanc (2011), the effects of absenteeism, poor job performance, accidents and injuries, and alcohol-related disability and death has been estimated to cost employers. Therefore, such conditions lead to loss of productivity that ultimately will become costly to the organizations. This loss of productivity manifests itself when employees who are under the influence of alcohol come to work with a hangover, feeling sleepy, lower output, poor work quality, and conflicts with colleagues and supervisors.

Computer Uses. According to Varma and Marler (2013), computer use is measured as a self-report measure of 'average number of hours of computer use per day'. Hence, with the 
emergence of computers and technology made available by computerization of office based work, may influence health and have negative consequences on workloads, deadlines, duration of computer usage and performance expectations (Jalil and Achan, 2013). The work environment for many office workers has significantly changed in modern times with the computerization of their office workplace. The usage of computers in work tasks, information storage and communication has provided many benefits to organizations and their staff such as increasing of productivity and efficiency of work performance and improving quality of professional service delivery to clients. Computerization of office work is one of the vital key factors for productivity as the young employees who are the Generation $Y$ find it easier and efficient to work with the right IT to help get the job done. As Generation Y depends on technology so much, it is crucial to consider the place of technology at workplace. These technology savvy generations have high expectations on their organizations in providing them with the latest technology they need to get the job done. With the ICT adoption, SMEs in Malaysia has helped SMEs owners to host their own official websites and gain competitive advantage. Hence, it is estimated that at least $56 \%$ of SMEs employees use computers for more than half of their working day (Adham and Ahmad, 2004).

\subsection{Methodology}

In the theoretical framework for this research is developed based on previous studies. The independent variables are the individual characteristics of Generation $Y$ which are age, gender, physical activity, alcohol drinking habits, smoking habits and Computer Use Information, while the dependent variable is the Generation Y's job performance. Based on the research objectives and research framework developed, the following hypotheses are proposed:

H1: $\quad$ Physical Activity can significantly influence Gen Y employees' job performance H2: $\quad$ Smoking habits can significantly influence Gen Y employee's job performance.

H3: $\quad$ Alcohol drinking habits can significantly influence employee's job performance.

H4: $\quad$ Computer uses can significantly influence and Gen Y employees' job performance.

Population/Sample. The population for this study consists of 373 employees who are working in SME companies in Kuching, Sarawak, Malaysia. The sample size was 111, and this gives a response rate of $29.7 \%$, which is a low but acceptable response rate in most research studies in Malaysia (Ng and Anuar, 2011; Ng et al., 2011; and Sekaran, 2003). The sampling technique employed in the present study based on purposive sampling. Purposive sampling is being chosen because the information obtained from specific target groups, and they were the office workers from various sectors of SME companies in Kuching, Sarawak. These Generation Y employees are the office workers who perform their work in sedentary, computer-intensive jobs that require at least more than four hours per day at the office computer and at least six hours per day sitting in an office chair.

Survey Instrumentation. The survey instrument used for data collection was a survey 
questionnaire. The scales used in the present study adapted from previous office environment studies. The questionnaire employed in the present study consists of questions that measure the individual characteristics taken from the Work-style Survey (Feuerstein et al., 2005). The questionnaire consists of frequency of physical activity enough to perspire, smoking habits, alcohol drinking habits and computer information to indicate individual characteristics. The items were mainly on a four point scale (Never - At least three times per week) for Q26 - Q27, on three-point scale (Less than - At least three times per week) for Q25, on three-point scale (Never - At least three times per week) for Q28, on three-point scale (Not at all - Every day) for Q29 or a dichotomous scale (yes-no) for Q31-32 and Q34. The questionnaire on job performance was based on Bormon and Motowidlo (1993).

\subsection{Results and Discussions}

Respondents Profile. Detailed breakdown of respondents profile is furnished at Table 1 of this report. Out of the 111 randomly distributed questionnaires a total of 93 questionnaires, or $83.7 \%$, were collected. However, only 67 sets of questionnaire were found to be satisfactorily completed. Most of these young employees (35 respondents $52.2 \%$ ) were female, and 32 respondents (47.8\%) were male. 58 respondents $(86.6 \%)$ were single, and only nine respondents (13.4\%) were married. A total of 36 respondents $(53.7 \%)$ were from the age group of between 25 and below years old, 23 respondents or $34.3 \%$, were between 26-30 years old, and 8 respondents $(11.9 \%)$ were $31-35$ years old. $34.3 \%$ of the respondents have certificate or diploma education, of which about $46.3 \%$ with bachelor's degree, while about $13 \%$ have a master's degree, Ph.D or higher. About $40.3 \%$ respondents have less than one year work experience, while the rest of $34.3 \%$ have one to five years work experience. $10.4 \%$ of respondents have six to ten years' experience, and $14.9 \%$ respondents have more than ten years' work experience.

Table 1: Demographic characteristics of respondents

\begin{tabular}{|l|l|l|l|}
\hline Variables & Categories & Frequency & Percentage(\%) \\
\hline Gender & Female & 35 & 52.2 \\
& Male & 32 & 47.8 \\
\hline Marital Status & Single & 58 & 86.6 \\
& Married & 9 & 13.4 \\
\hline Age & 25 and below & 36 & 53.7 \\
& $26-30$ years & 23 & 34.3 \\
& $31-35$ years & 8 & 11.9 \\
\hline Education Level & Certificate / Diploma & 23 & 34.3 \\
& Bachelor's Degree & 31 & 46.3 \\
& Master's Degree, PhD or Higher & 13 & 19.4 \\
\hline Working Experience & Less than 1 year & 27 & 40.3 \\
& $1-5$ years & 23 & 34.3 \\
& $6-10$ years & 7 & 10.4 \\
& More than 10 years & 10 & 14.9 \\
\hline
\end{tabular}


Correlation Analysis. In order to navigate the discussion, the following Table 2 summarizes overall hypotheses being contended in the present study.

Table 2: Summary of overall hypotheses

\begin{tabular}{|l|l|l|l|l|}
\hline Hypotheses & Individual Characteristics & Correlation, $R$ & $\begin{array}{l}\text { Strength } \\
\text { (Hair, Black, Babin, } \\
\text { and Tatham 2006) }\end{array}$ & Decision \\
\hline H1 & Physical Activity & $-.311^{*}$ & Weak & Not rejected \\
\hline H2 & Smoking Habits & $.412^{* *}$ & Moderate & Not rejected \\
\hline H3 & Alcohol Drinking Habits & $-.415^{* *}$ & Moderate & Not rejected \\
\hline H4 & Computer Uses & $-.262^{*}$ & Weak & Not rejected \\
\hline \multicolumn{4}{|c}{ *. Correlation is significant at the 0.05 level (2-tailed), $N=67$} \\
**. Correlation is significant at the 0.01 level (2-tailed), $N=67$
\end{tabular}

Table 2 presents the correlations between individual characteristics and job performance. The result shows that the correlation between smoking habits and job performance is positively significant $(R=0.412, p<0.01)$ and moderate in strength. Therefore, $H 2$ is not rejected. Most respondents believe that smoke breaks among employees are not only considered disruptive during work but also decrease their job performance. This characteristic reflects positively on the job performances of the Generation $Y$. The results suggest that alcohol drinking habit is negatively and significantly correlate to the job performance of the Generation $\mathrm{Y}$. Hence, $\mathrm{H} 3$ is not rejected. It is believed that the Generation Y cope with their stresses by drinking (Teagle, Mueller and Lockshin, 2010), though it believed that alcohol drinking habit has been shown to cause significant low productivity among office workers (Marchand and Blanc, 2011). Due to disagreements, respondents may feel that this characteristic can subdue the job performance among the Generation Y. Besides that, it is also found that physical activity is statistical significant but at negative direction correlated with job performance $(R=-0.311, p<0.01)$. Even though the correlation strength is weak, the relationship is still significant, which means that $\mathrm{H} 1$ is not rejected. The finding suggests that these young employees who do not engage in physical activity before work were still found to be able to handle workload demands. This result also indicates that the Generation $Y$ employees were still able to concentrate on their work with less indulge in physical activities. Hence, there may be some respondents who do not respond as enthusiastically to the benefits of exercises from physical activity that appear to be not entirely well-suited with their work performance. Also, the results suggest that there is a negatively significant correlation between computer uses and job performance $(R=$. $0.262, p<0.01)$. The correlation strength may be weak, but the relationship is significant, which means $\mathrm{H} 4$ is not rejected. Although computer usage has provided many benefits such as increasing of productivity and efficiency of work performance (Adham and Ahmad, 2004); the computer use may be less important to the Generation $Y$ since this generation is technology savvy and working long hours is crucial for their job and career achievements (Kelan et al., 2009). 


\subsection{Conclusion}

The purpose of this study was to examine the impact of personal characteristics of the Generation Y, who employed in the Malaysian SMEs. It also discussed the importance to understand the characteristics of these young workers. This study focused on the individual characteristics namely: physical activity, smoking, drinking, and duration of computer use before taking breaks on performance at work. The data revealed an interesting insight into this new generation and how their social habits affected their job performance. The initial results confirmed the characteristics that are attributed to Generation $Y$ employees' performance at work. After analysis, the results revealed that not all of the characteristics (physical activity, smoking, drinking, and duration of computer use before taking breaks) had an influence on Generation $Y$ job performance at the work place at SMEs. The results of correlation analysis that determine the factors that affecting the Generation $Y$ performance at work specifically at SMEs, social habit (smoking and drinking alcohol) among the Generation $Y$ was found to affect their job performance significantly, and this was consistent with findings reported by previous researchers. Although it showed biases in response, smoking was perceived as remedy among smokers (rather than taking tit-bits) whenever they experienced stress or mind blocking at work place.

This study found that alcohol drinking habits moderately influence on the job performance among the Generation $Y$ employees, and this denoted that these young employees tended to choose drinking alcohol as a means to cope with their stresses at work. The 1996 Code of Practice of the International Labour Office (ILO) discusses alcohol problems as health issues and recommends employers emphasized prevention and offered assistance to employees who met it. Nevertheless, individual employers were left to set their own alcoholrelated policies thus the approaches they adopted vary. Many explicitly prohibited alcohol at work and providing interventions to employees with alcohol problems, such as through employee assistance programs (EAPs). Irrespective of the jurisdiction the employers chose, what is needed is apparently the need for a clear and strict alcohol policy

Since studies had found that the Generation Y preferred to work long hours, the researchers conclude that this had led them to indulge less in physical activities as a remedy to cope with stress at work. Although many organizations of sufficient size provided employee assistance programs (EAPs) such as work-out facilities as a fringe benefit for their employees, it seemed that they still prefer other means as a remedy for their work-related stress. It was the reason the findings derived from this study showed that physical activities had little impact on the job performance of the Generation Y employees in Malaysia.

This study was not without limitations. Several limitations were evident and must be deliberated further. The sample size was restricted those working in the SMEs and to populations in one major city due to the inability of reaching out to other parts of the country (Malaysia) to solicit more respondents to participate in this study. Thus, conclusions might imply ambiguity. Secondly, the present study was a correlation study with a limited period and done at one point in time. The results might vary if the study was done at another point of time or if the study was based on a longitudinal study. Nonetheless, future studies need to focus on a much larger sample size in order to capture a higher generalization impacts. This 
study cannot be generalized, and the results cannot fully represent all generations of Malaysians on this topic. It is merely an attempt to define the concepts of individual characteristics and job performance of the generation $Y$ employees working in the SMEs from a Malaysian perspective.

\section{References}

Adham, K.A. and Ahmad, M. (2004). Adoption of Web Site and E-Commerce Technology Among Malaysian Public Companies. Industrial Management and Data Systems, 105(9), 1172-1187.

Borman, W. C., (2004). The concept of organizational citizenship. Current Directions in Psychological Science 13(6), 238-241.

Borman, W. C., and Motowidlo, S. J. (1993). Expanding the Criterion Domain to Include. Elements of Contextual Performance. In N. Schmidt, W. C. Borman, A. Howard, A. Kraut, D. Ilgen, B. Schneider, \& S. Zedeck (Eds.), Personnel Selection in Organizations, 71-98.

Conway, TL, Woodruff, SI, \& Hervig, LK, "Women's smoking history prior to entering the US Navy: A prospective predictor of performance," Tobacco Control 16:79-84, 2007.

Eltayeb S, Staal J, Hassan A, de Bie R. Work related risk factors for neck, shoulder and arms complaints: a cohort study among Dutch computer office workers. J Occup Rehabil. 2009;19(4): 315-22.

Feuerstein, M., Nicholas, R. A., Huang, G. D., Haufler, A. J., Pransky, G., \& Robertson, M. (2005). Workstyle: Development of a Measure of Response to Work in Those With Upper Extremity Pain: Journal of Occupational Rehabilitation Vol 5(2) Jun 2005, 87-104.

Feuerstein M, Shaw WS, Nicholas RA, Huang GD. (2004) From confounders to suspected risk factors: psychosocialfactors and workrelated upper extremity disorders. J Electromyogr Kinesiol. 14:171-8.

Gerr F, Monteilh CP, Marcus M. (2006). Keyboard use and musculoskeletal outcomes among computer users. J Occup Rehabil. 16:265-77.

Griffin, M. A., Neal, A., Neale, M. (2000). The contribution of task performance and contextual performance to effectiveness: investigating the role of situational constraints. Applied Psychology: An International Review 49(3), 517-533.

Gursoy, D., Maier, T. A., \& Chi, C. G. (2008). Generational differences: an examination of work values and generational gaps in the hospitality workforce. International Journal Hospitality Management, 27, 448-458.

Hair, J.F., Black, W.C., Babin, A.L., Tatham, R.L. (2006) Multivariate Data Analysis. 6th Edition. Pearson Prentice Hall. Upper Saddle River, New Jersey.

Islam, M., Cheong, T. W., Yusuf, D. H. M., \& Desa, H. (2011). A Study on 'Generation Y' Behaviours at Workplace in Penang. Journal of Applied Sciences Research, 7(11).

IJmker S, Huysmans MA, Blatter BM, van der Beek AJ, van Mechelen W, Bongers PM (2007) Should office workers spend fewer hours at their computer? A systematic review of the literature. Occup Environ Med 64(4):211-222. 
Janwantanakul P, Pensri P, Jiamjarasrangsri W, Sinsongsook T (2008) Prevalence of self-reported musculoskeletal symptoms among office workers. Occup Med (Lond) 58:436-438

Kelan, E., L. Gratton, A. Mah and L. Walker, 2009. The Reflexive Generation: Young Professionals' Perspectives on Work, Career and Gender. London Business School.

Lundborg, P. (2007). "Does smoking increase sick leave? Evidence using register data on Swedish workers," Tobacco Control 16:114-118.

Maniam T. (1994). Drinking habits of Malaysians in general practice. Med J Malaysia Vol 49 No 4 Dec 1994.

Marchand, A.; Blanc, M.E. (2011). Occupation, Work Organization Conditions, and Alcohol Misuse in Canada: An 8-Year Longitudinal Study. Subst. Use Misuse, 46, 1003-1014.

Miranda, H., Viikari-Juntra, E., Martikainen, R., Takala, E., \& Riihimaki, H. (2001). Physical exercise and musculoskeletal pain among forest industry workers. Scandinavian Journal of Medicine and Science in Sports, 11, 234-246.

Ng, P. K. and Anuar, N. I., 2011. "A Case Study on the Importance of Knowledge Management in Creative roductdevelopment". IEEE International Conference on Industrial Engineering and Engineering Management. Singapore. pp. 669-673.

Ng, P. K., Goh, G. G. G. and Eze, U. C., 2011. The Importance of CAD and Knowledge Management in Concurrent Engineering Project Performance. Journal of Information and Knowledge Management, 10(4), pp. 365-378.

Ortho-McNeil (2008). A 10-year update of Ortho-McNeil's Survey on the impact of pain on the workplace. Pain in the workplace [On-line]. Available: http://www.painandwork.com/painandwork/pages/index.jsp

Sarawak (2010), Department of Statistics, Yearbook of Statistics 2010, Government Printers, Kuala Lumpur.

Sekaran, U., 2003. Research Methods for Business: A Skill Building Approach (4th ed.). New York: John Wiley \& Sons.

Sonnentag,S.,\&Zijlstra,F.R.H.(2006).Job characteristics and off-job activities as predictors of need for recovery, well-being, and fatigue. Journal of AppliedPsychology, 91, 330-350.

Susana William Jalil and Pauline Achan (2013), "The influence of Workstyle and Job Performance among Office Workers at SMEs in Malaysia", Proceedings ICBERG, Penang.

Teagle, J., Mueller, S. and Lockshin, L. (2010), "How do Millennials' wine attitudes and behavior differ from other generations?", Proceedings 5th International Academy of Wine Business Research Conference, Auckland.

Varma, S., \& Marler, J. H. (2013). The dual nature of prior computer experience: More is not necessarily better for technology acceptance. Computers in Human Behavior, 29(4), 1475-1482.

Village J, Rempel D, Teschke K. (2005). Musculoskeletal disorders of the upper extremity associated with computer work: A systematic review. Occup Ergon 2005, 5:205-218.

Wong, Annie. M. N. (2009), "The Performance and Roles of the Small and Medium Enterprises (SMEs) in the Manufacturing Sector in Sarawak", Small and Medium Enterprises (SMEs) in Sarawak-Strategies to Enchance their Competitiveness, University Publication Center (UPENA), UiTM. 